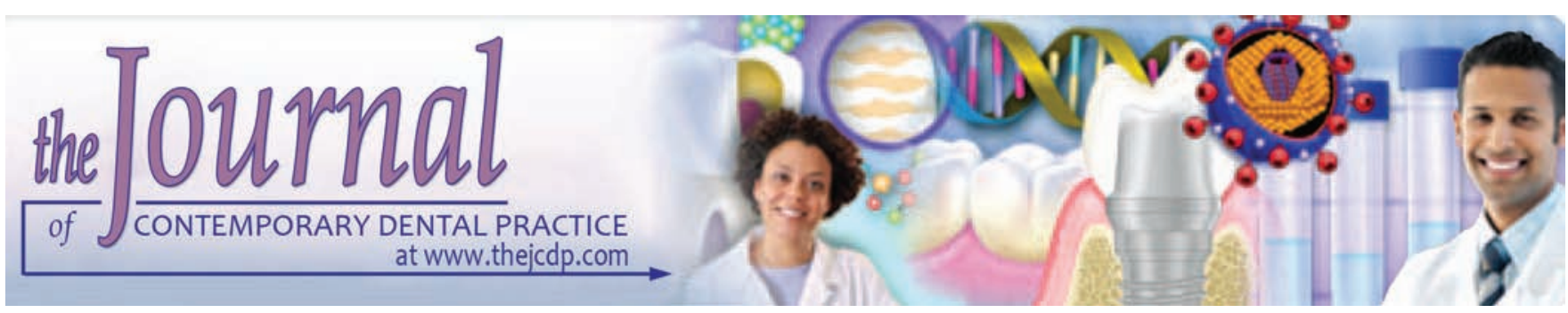

\title{
Oral Leukoplakia: Clinicopathological Correlation and Its Relevance to Regional Tobacco-related Habit Index
}

\author{
${ }^{1}$ Prashanth Shetty, ${ }^{2}$ Shweta Hegde, ${ }^{3} \mathrm{KS}$ Vinod, ${ }^{4}$ Salona Kalra, ${ }^{5}$ Prasoon Goyal, ${ }^{6}$ Mimansha Patel
}

\begin{abstract}
Introduction: A case control study was carried out to evaluate the synergistic effects of habits quantified by habit index and its effect and severity on the clinicopathological features of oral leukoplakia in a cohort of 100 patients visiting Triveni Dental College, Bilaspur, Chhattisgarh, India.
\end{abstract}

Materials and methods: One hundred patients indulging in tobacco-related habits (smoking and smokeless forms) were categorized into two groups: A case/experimental group consisting of 50 patients presenting with oral leukoplakia lesion and a control group consisting of 50 patients with no clinical signs of oral leukoplakia. Habit index was calculated in both groups. Case group was further subjected to incisional biopsy of the lesion followed by histopathological examination. All the variables in the study were statistically analyzed for the mean, standard deviation, i.e., value of central tendency, z-test, test of significance, and Pearson's correlation (r-test).

Results: For $p<0.05$ bidi habit index was significantly higher in the case group. Higher bidi habit index was evident in the severe stages of lesion ice, $p<0.001$ (highly significant). The degree of dysplasia was higher with advancing clinical stage of the lesion.

Conclusion: Higher bidi habit index in the case group contributed significantly for severe stages of lesion and thereby

\footnotetext{
${ }^{1}$ Department of Prosthodontics, Triveni Institute of Dental Sciences, Hospital and Research Centre, Bilaspur, Chhattisgarh India

${ }^{2,4}$ Department of Oral Medicine and Radiology, Triveni Institute of Dental Sciences, Hospital and Research Centre, Bilaspur Chhattisgarh, India

${ }^{3,6}$ Department of Oral Pathology and Microbiology, Triveni Institute of Dental Sciences, Hospital and Research Centre Bilaspur, Chhattisgarh, India

${ }^{5}$ Department of Public Health Dentistry, Triveni Institute of Dental Sciences, Hospital and Research Centre, Bilaspur Chhattisgarh, India

Corresponding Author: Prashanth Shetty, Professor, Department of Prosthodontics, Triveni Institute of Dental Sciences, Hospital and Research Centre, Bilaspur, Chhattisgarh, India, Phone: +919179020345, e-mail: dr.prashanths@gmail.com
}

indicates its probable progression toward malignancy. Nonhomogenous leukoplakia of the speckled subtype exhibited moderate and severe epithelial dysplasia. Hence, quantification of tobacco-related habits and the clinical appearance of the premalignant lesion predict the risk of subsequent malignant transformation of the disease.

Keywords: Epithelial dysplasia, Habit index leukoplakia, Tobacco-related habits.

How to cite this article: Shetty P, Hegde S, Vinod KS, Kalra S, Goyal P, Patel M. Oral Leukoplakia: Clinicopathological Correlation and Its Relevance to Regional Tobacco-related Habit Index. J Contemp Dent Pract 2016;17(7):601-608.

Source of support: Nil

Conflict of interest: None

\section{INTRODUCTION}

Oral leukoplakia, the best known premalignant lesion, is the ultimate response of oral mucosa to persistent physical and chemical insult. The concept of oral premalignancy has matured dramatically in recent decades following the rejection of the precept that all such lesions must develop into malignancy if left untreated. We now define precancerous lesion as "morphologically altered tissue in which cancer is more likely to occur than its apparently normal counterpart." ${ }^{1}$

The term "leukoplakia" etymologically is derived from the Greek words "leukos," meaning white, and "plax," meaning plaque. ${ }^{2}$ At present, leukoplakia is defined as "[a] white plaque of questionable risk having excluded (other) known diseases or disorders that carry no increased risk for cancer." ${ }^{3}$ The health of the oral mucosa is determined by the influence of tobacco habits and diet, and therefore lesions, such as leukoplakia exhibit geographical and clinicopathological variations. Tobacco use is the most common risk factor for oral leukoplakia. Tobacco was introduced into Europe in the late 15th century. Sometime in the late 16 th or early 17 th century, Portuguese traders introduced it into India. Since then, 
there has been an exponential rise in the sale and consumption of tobacco across the country and through all sections of the society. Tobacco is addictive and its use is harmful to health in many ways. ${ }^{4}$ In India, about $33.3 \%$ (one-third) of men and $1.6 \%$ of women aged 15 to 49 years smoke tobacco. ${ }^{5}$ Indians consume tobacco predominantly in the form of smoking bidis ( $48 \%$ of total consumption), Chewing tobacco habits involve use of betel quid (betel leaf with tobacco, areca nut, and slaked lime), "gutkha" (dried mixture of betel quid and tobacco sold in attractive pouches), "mawa", "zarda" (flavored tobacco), or "khaini" (crude form of dried and ground tobacco with lime $-38 \%$ ), kharra (combination of tobacco, areca nut, lime and catechu), and "gudakhu" or "gul" (paste of powdered tobacco, molasses, lime, red soil, and water which is then applied to the gums and teeth with a finger). Only $14 \%$ of tobacco consumption is in the form of cigarettes. Various other proposed etiological factors for oral leukoplakia are alcohol, candida infection, chronic irritation (ill-fitting denture), dietary deficiency states, viruses, and galvanism. ${ }^{6}$ The evidence of biological tenability is furnished by the presence of many carcinogens in tobacco and its products, namely, tobacco-specific $N$-nitrosamines mainly comprising $N$-nitrosonornicotine (NNN) and 4-(methylnitrosamine)-1-(3-pyridyl)-1-butanone (NNK). These are constituted by $N$-nitrosation of nicotine which is the primary alkaloid responsible for tobacco addiction. The smoke emanating from tobacco consists of many gaseous and condensed tar particles. Many of the organic compounds, such as alkenes, nitrosamines, thiocyanate, carbon monoxide, ammonia, nitrogen oxide, aromatic and heterocyclic aromatic hydrocarbons, and amines are known to be genotoxic and carcinogenic. ${ }^{7,8}$ The factors of nutritional compromise and psychologic stress complicate the impact and frequency of the habits and make leukoplakia an early harbinger of oral malignancy.

Leukoplakia is clinically classified into a homogeneous type (flat, thin, and uniform white in color) and a nonhomogeneous type. The nonhomogeneous type has been defined as a white and red lesion ("erythroleukoplakia") that may be either irregularly flat (speckled) or nodular.

A provisional diagnosis is made when clinically a lesion exhibiting white appearance cannot be clearly diagnosed as any other disease of the oral mucosa, and definitive diagnosis of oral leukoplakia is made following identification and elimination of possible etiological factors and subsequent histopathological examination in the case of stubborn lesions. ${ }^{9}$ Leukoplakia is proposed to be considered the most common potentially malignant disorder of the oral mucosa. ${ }^{10}$ Lesions with certain features are more prone to undergo malignant transformation, but no apparent clinical attributes can bring certitude. It is, therefore, imperative to designate premalignant disorders of the oral mucosa, such as leukoplakia, erythroplakia, or erythroleukoplakia with a histological marker, such as epithelial dysplasia before any definitive or long-term follow-up is initiated. Epithelial dysplasia is defined as ${ }^{11}$ "a pre-cancerous lesion of stratified squamous epithelium characterized by cellular atypia and loss of normal maturation and stratification short of carcinoma in situ," while carcinoma in situ is defined as "a lesion in which the full thickness, or almost the full thickness, of squamous epithelium shows the cellular features of carcinoma without stromal invasion." The criterion used for diagnosing these changes are "the more prominent or numerous they are, the more severe the grade of dysplasia". On the basis of this, lesions are graded into mild, moderate, and severe epithelial dysplasia. The presence of epithelial dysplasia reflects a disturbance in the homeostatic control mechanism of the epithelium and is generally accepted as an important predictor of malignant development in premalignant lesion. ${ }^{11}$

\section{MATERIALS AND METHODS}

This study was undertaken in the department of Oral Medicine and Radiology, Triveni Institute of Dental Sciences, Hospital and Research Centre, Chhattisgarh, India, to study the clinicopathological characteristics of oral leukoplakia and its correlation with habit index.

A thorough clinical examination was done and recorded in a standard pro forma. A formal ethical clearance to conduct this study was obtained by the ethical committee of the institution. The procedures followed were in accordance with the ethical standards of the responsible committee on human experimentation (institutional or regional) and with the Helsinki Declaration of 1975, as revised in 2000. Patients selected for the study were explained in detail about the condition affecting their oral cavity and the procedure that they would be subjected to. An informed written consent was sought from all of them after explaining the whole procedure in Hindi/local language for easy understanding of what procedures they would be subjected to.

The objectives of this study were to:

- Compare the clinicopathological picture of oral leukoplakia and

- To correlate clinical severity with habit index.

The purpose of research was to develop a model in which experimental group can be compared scientifically with a control group. In this study, we made two groups of 50 patients each, who were serially and randomly included for the study. A detailed case history was recorded for all patients with special reference to their tobacco-related habits - such as bidi, cigarette, and hookah smoking and paan, zarda, gutka, and supari chewing - or any other habits, its type, duration, and frequency of use per day. All patients were subjected to a 


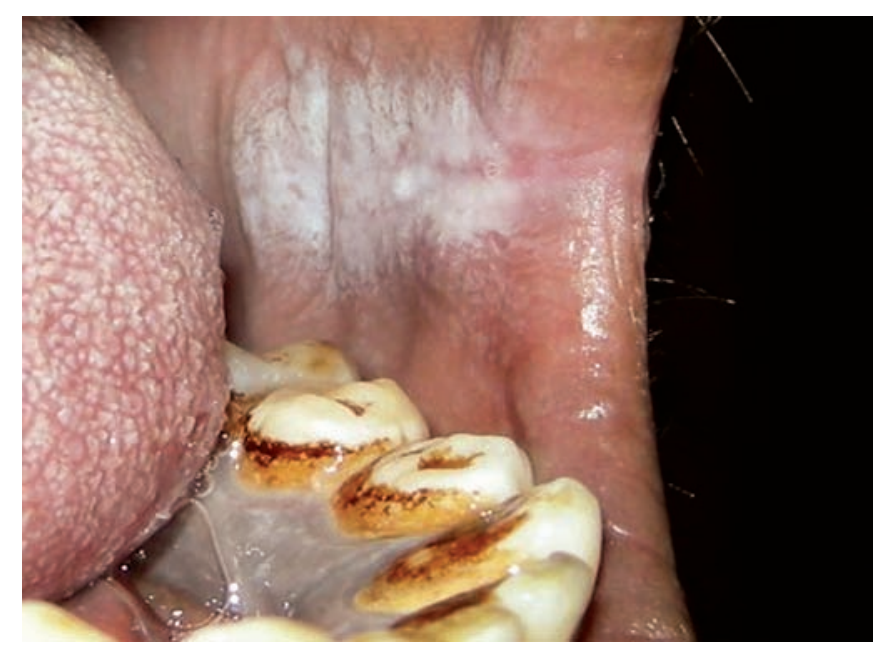

Fig. 1: Clinical photograph of homogenous leukoplakia

thorough general physical and oral clinical examination, and details were recorded on standard pro forma. Patients were referred to the department of prosthodontics for correction of faulty prosthesis and coronoplasty of the sharp teeth which might have caused exacerbation of the existing leukoplakia lesion. Protective splints were designed for some patients as part of habit counseling and elimination of premature interference.

The experimental group constituted of 50 patients who indulged in tobacco abuse in any form, such as snuff, chewing/dipping, and smoking habits, i.e., cigarettes or bidi, a native cigarette-like stick of coarse tobacco handrolled in a dry tembhurni (Diospyros melanoxylon) leaf and who presented with tangible mucosal lesion, such as leukoplakia, diagnosed on the basis of clinical appearance and the histopathology of which indicated dysplastic features. The control group comprised of 50 patients who reported tobacco or alcohol abuse for reasonable duration and yet did not present with any detectable lesion in the oral mucosa.

Habit index was calculated using the following:

Habit Index = Duration of habit in years multiplied by number of bidi pieces/gutka pouches (tobacco smoking/ chewing respectively) per day.

In those patients in which leukoplakia was present, the site of involvement included examination of buccal mucosa, labial mucosa, palate, tongue, floor of the mouth, the size and extent of the lesion, whether lesion was scrapable or not, and whether the lesion presented with candidal superimposition. All these were recorded in detail.

After establishing the provisional clinical diagnosis of leukoplakia, whether homogenous/nonhomogenous (inclusive of speckled, nodular, verrucous leukoplakia), the patients were subjected to routine investigations that comprised of blood examination in order to rule out any underlying systemic conditions. This was followed by a histopathological confirmation of diagnosis

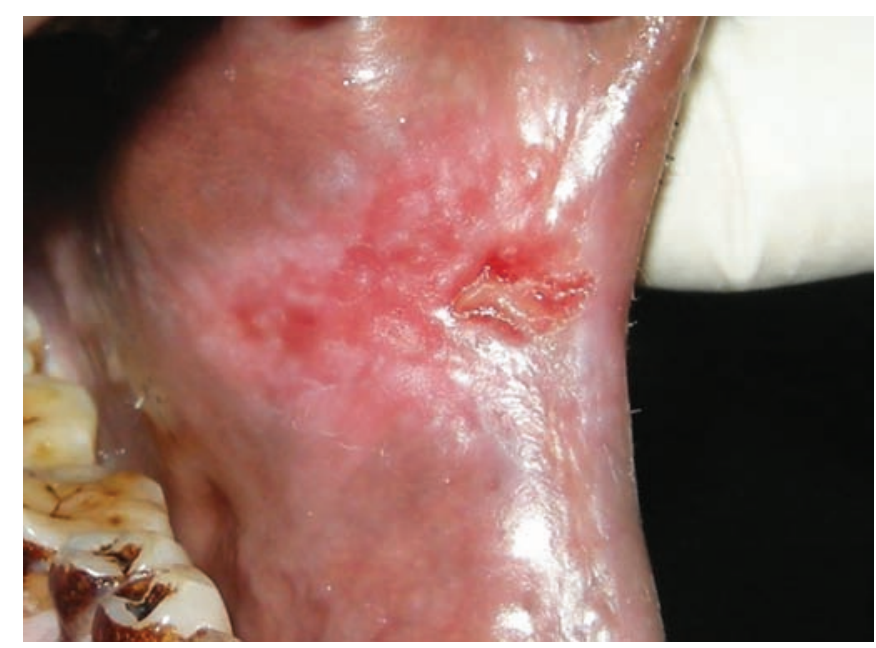

Fig. 2: Clinical photograph of speckled leukoplakia

by performing an incisional biopsy of the lesion. Clinical and pathological grading of patients with leukoplakia lesion was done using the modified OL staging method suggested by van der $\mathrm{Waal}^{3}$ in his study and adapted from van der Waal and Axéll. ${ }^{12}$

Clinical grouping was done on the basis of either:

- Homogeneous type (flat, thin, and uniform white in color) (Fig. 1) or

- Nonhomogeneous type (white and red lesion ("erythroleukoplakia"), which may be either irregularly flat (speckled) or nodular or verrucous leukoplakia or proliferative verrucous leukoplakia subtype (Fig. 2).

\section{Histopathological Grading ${ }^{13}$}

Squamous hyperplasia: This may be in the spinous layer (acanthosis) and/or in the basal/parabasal cell layers (basal cell hyperplasia); the architecture shows regular stratification without cellular atypia.

Mild dysplasia: The architectural disturbance is limited to the lower third of the epithelium accompanied by cytological atypia (Fig. 3).

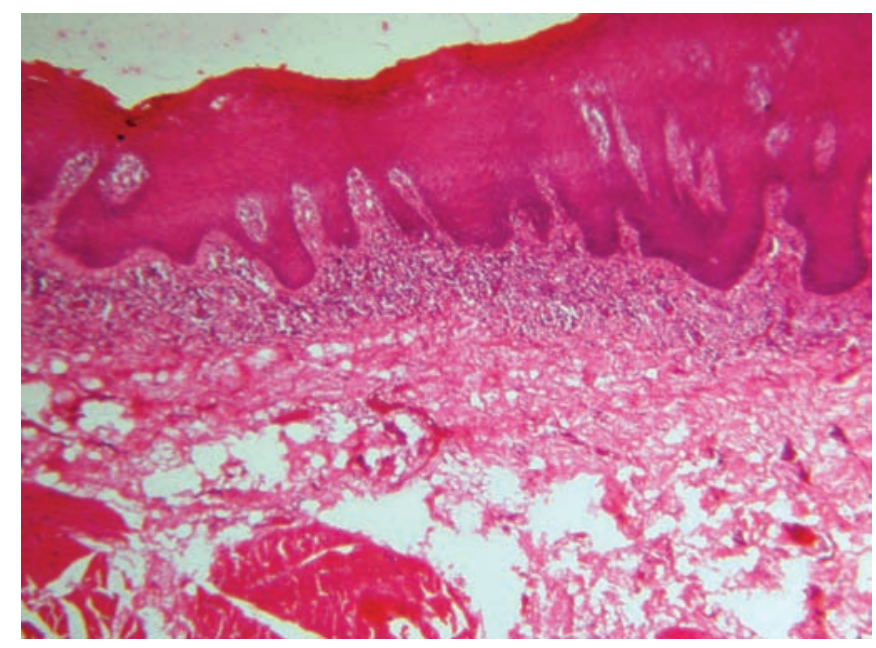

Fig. 3: Histopathology showing mild epithelial dysplasia (H\&E stain, 10×) 


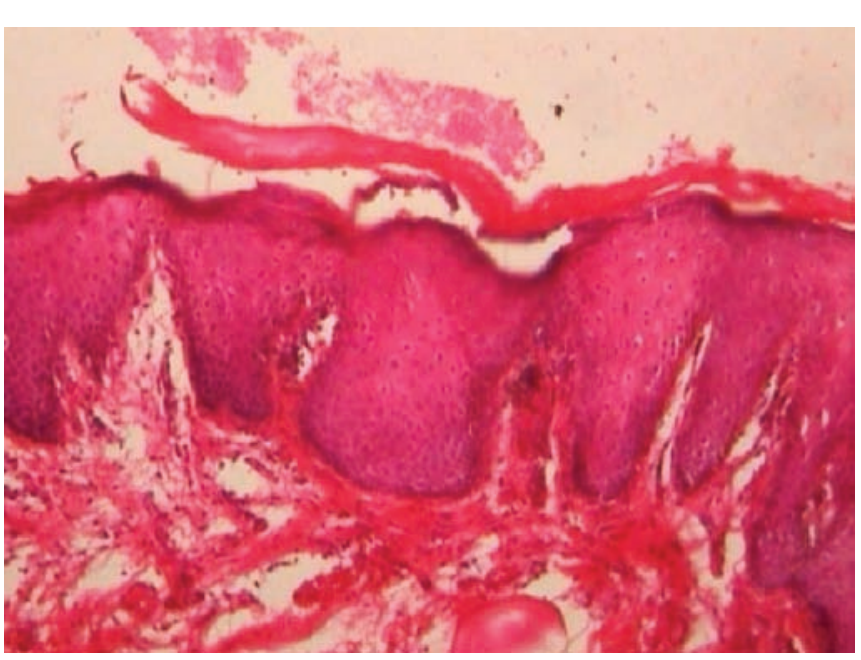

Fig. 4: Histopathology showing moderate epithelial dysplasia (H\&E stain, 10×)

Moderate dysplasia: The architectural disturbance extends into the middle third of the epithelium; consideration of the degree of cytological atypia may require upgrading (Fig. 4).

Severe dysplasia: The architectural disturbance involves more than two-thirds of the epithelium; architectural disturbance into the middle third of the epithelium with sufficient cytologic atypia is upgraded from moderate to severe dysplasia.

Carcinoma in situ: Full thickness or almost full-thickness architectural disturbance in the viable cell layers accompanied by pronounced cytological atypia (Fig. 5).

\section{Classification and Staging System for Oral Leukoplakias (OL system) $)^{3,12}$}

\section{Size of the Leukoplakia (L)}

- $\mathrm{L}_{1}$ - size of single or multiple leukoplakias together $<2 \mathrm{~cm}$

- $\mathrm{L}_{2}$ - size of single or multiple leukoplakias together 2 to $4 \mathrm{~cm}$

- $\mathrm{L}_{3}$ - size of single or multiple leukoplakias together $>4 \mathrm{~cm}$

- $\mathrm{L}_{\mathrm{X}}$ - size not specified.

\section{Pathology $(P)$}

- $\mathrm{P}_{0}$ - no epithelial dysplasia (includes "no or perhaps mild epithelial dysplasia")

- $\mathrm{P}_{1}$ - mild or moderate epithelial dysplasia

- $\mathrm{P}_{2}$ - severe epithelial dysplasia

- $\mathrm{P}_{\mathrm{x}}-$ absence or presence of epithelial dysplasia not specified in the pathology report.

\section{OL Staging System}

- Stage I- $\mathrm{L}_{1} \mathrm{P}_{0}$

- Stage II $-\mathrm{L}_{2} \mathrm{P}_{0}$

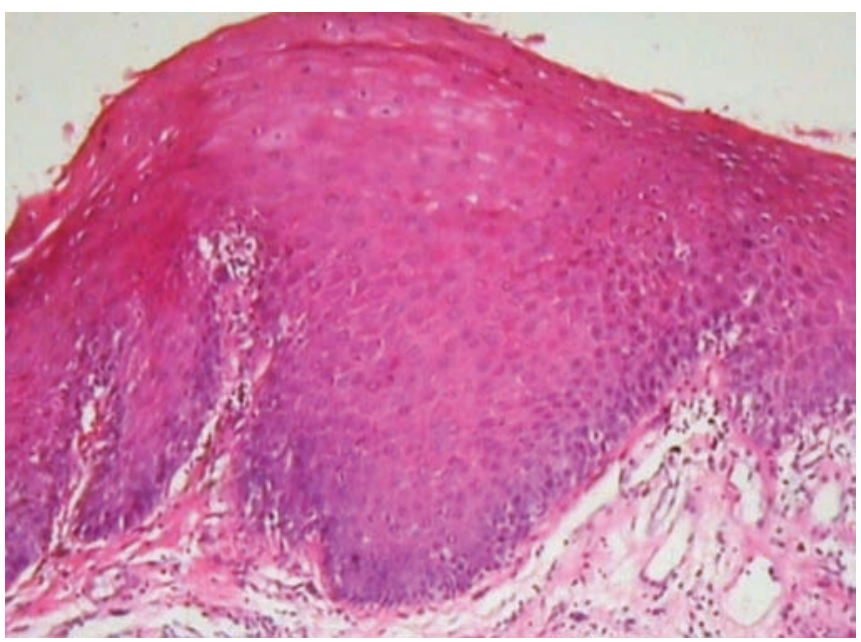

Fig. 5: Histopathology showing carcinoma in situ (H\&E stain, 45×)

- Stage III $-\mathrm{L}_{3} \mathrm{P}_{0}$ or $\mathrm{L}_{1} \mathrm{~L}_{2} \mathrm{P}_{1}$

- Stage IV $-\mathrm{L}_{3} \mathrm{P}_{1}$ or any $L \mathrm{P}_{2}$

\section{Statistical Considerations}

All the variables in the study were statistically analyzed for the mean, standard deviation (i.e., value of central tendency), z-test (i.e., test of significance), and Pearson's correlation (r-test).

- $\operatorname{Mean}=\frac{\sum X \mathrm{Xi}}{\mathrm{n}}$

where $\mathrm{X} i=$ sum of all observations $\mathrm{n}=$ number of observations

- Standard deviation $(\mathrm{SD})=\sqrt{\frac{\sum(\overline{\mathrm{X}} \mathrm{i}-\mathrm{X})^{2}}{\mathrm{n}-1}}$

where $\mathrm{X} i=$ individual values

$$
\bar{X}=\text { mean; } \mathrm{n}=\text { number of observations. }
$$

\section{Z-Test}

The test requires the following to be known: $\sigma$ (the standard deviation of the population).

First, calculate the standard error (SE) of the mean:

$$
\mathrm{SE}=\frac{\sigma}{\sqrt{n}}
$$

The formula for calculating the $\mathrm{Z}$ score for the Z-test is as follows:

$$
z=\frac{x-\mu}{S E}
$$

where $x$ is a mean score to be standardized, and $\mu$ is the mean of the population.

\section{RESULTS AND DISCUSSION}

Evaluation of the frequently used form of habit indicates that 49 patients out of 50 in the case group indulged in 
Oral Leukoplakia: Clinicopathological Correlation and Its Relevance to Regional Tobacco-related Habit Index

Table 1: Mean \pm SD of various parameters of case and control group patients

\begin{tabular}{|c|c|c|c|c|}
\hline \multirow[b]{2}{*}{ Parameters } & \multicolumn{2}{|c|}{ Group } & \multirow[b]{2}{*}{$p$-value } & \multirow[b]{2}{*}{ Significance } \\
\hline & Case & Control & & \\
\hline Bidi smoking duration (in years) & $\begin{array}{l}23.61 \pm 9.34 \\
(n=49)\end{array}$ & $\begin{array}{l}19.76 \pm 12.04 \\
(n=50)\end{array}$ & $>0.05$ & NS \\
\hline Bidi frequency/day & $\begin{array}{l}18.67 \pm 9.96 \\
(n=49)\end{array}$ & $\begin{array}{l}7.98 \pm 5.57 \\
(n=50)\end{array}$ & $<0.001$ & HS \\
\hline Bidi index & $\begin{array}{l}474.51 \pm 374.10 \\
(n=49)\end{array}$ & $\begin{array}{l}165.75 \pm 136.19 \\
(n=50)\end{array}$ & $<0.001$ & HS \\
\hline Cigarette smoking duration & $\begin{array}{l}22.50 \pm 20.50 \\
(n=2)\end{array}$ & $\begin{array}{l}10.00 \pm 0.00 \\
(n=1)\end{array}$ & - & - \\
\hline Cigarette frequency/day & $\begin{array}{l}52.67 \pm 68.84 \\
(n=3)\end{array}$ & $\begin{array}{l}8.00 \pm 0.00 \\
(n=1)\end{array}$ & - & - \\
\hline Cigarette smoking index & $\begin{array}{l}131.00 \pm 127.00 \\
(n=2)\end{array}$ & $\begin{array}{l}80.00 \pm 0.00 \\
(n=1)\end{array}$ & - & - \\
\hline Hookah index & $\begin{array}{l}61.67 \pm 44.87 \\
(n=6)\end{array}$ & $\begin{array}{l}80.00 \pm 30.82 \\
(n=3)\end{array}$ & $>0.05$ & NS \\
\hline Chewing tobacco duration & $\begin{array}{l}8.00 \pm 5.74 \\
(n=10)\end{array}$ & $\begin{array}{l}8.33 \pm 5.74 \\
(n=3)\end{array}$ & $>0.05$ & NS \\
\hline Chewing tobacco frequency/day & $\begin{array}{l}6.20 \pm 6.24 \\
(n=10)\end{array}$ & $\begin{array}{l}5.00 \pm 2.16 \\
(n=3)\end{array}$ & $>0.05$ & NS \\
\hline Chewing tobacco index & $\begin{array}{l}44.36 \pm 45.55 \\
(n=10)\end{array}$ & $\begin{array}{l}50.33 \pm 50.15 \\
(n=3)\end{array}$ & $>0.05$ & NS \\
\hline
\end{tabular}

NS: Nonsignificant; HS: Highly significant

bidi smoking, the most commonly employed form of tobacco smoking habit prevalent. This observation is supported by the other studies. ${ }^{3,14-16}$ All the habit patterns were converted into habit index, and the numerical values were statistically analyzed. For $\mathrm{p}<0.001$, bidi index was significantly higher in the experimental group (Table 1). Other habits hookah, cigarette smoking, and tobacco chewing indicated almost similar indices. Although, all the 50 patients in the control group were bidi smokers, it is evident from Graph 1 that the bidi index of this group was significantly lower than the case group. The results of our study reveal that the dosedependent response attributing to higher bidi index

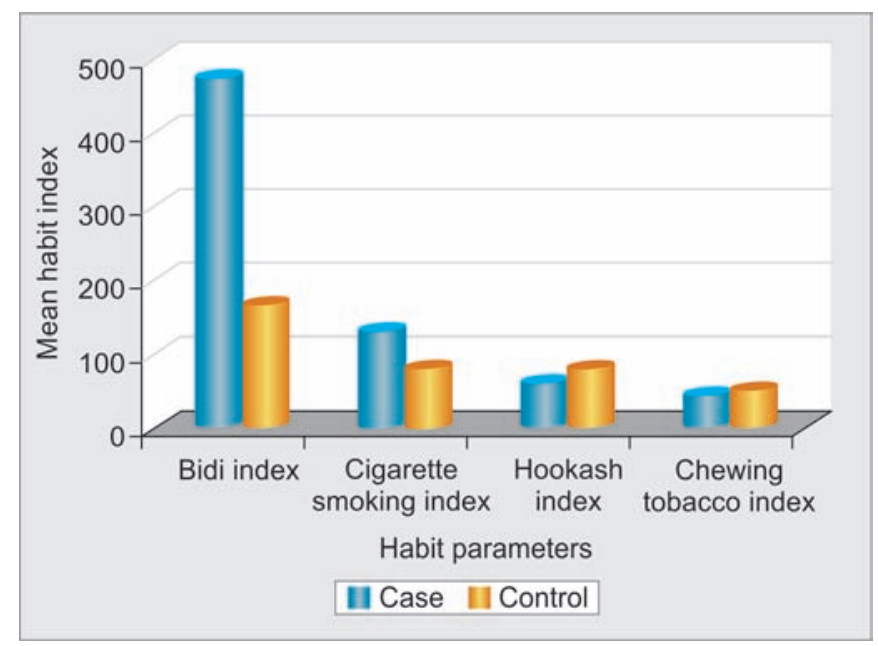

Graph 1: Mean of various tobacco-related habit index in case and control group was associated with severe epithelial dysplasia. Similar feature is emphasized in the studies of Bánóczy et al, ${ }_{1}^{17}$ Daftary et al, ${ }^{6}$ Dietrich et al, ${ }^{18}$ Gupta, ${ }_{19}$ and Macigo et al. ${ }^{20}$ All forms of tobacco produce free radicals that deplete antioxidants like Vitamin C, Vitamin E, and carotenoids and cause oxidative damage to DNA, proteins, and lipids. Concentrations of nicotine, tar, and other toxic agents are higher in bidis than in cigarettes, and bidi smoking has a greater physiological and biochemical effect than cigarette smoking. ${ }^{21}$ It is evident from the current study that the advances in the clinicopathologic stage of the lesion in the case or experimental group is attributable to higher habit index, especially bidi smoking (Table 2). Studies of Mehta and Hamner ${ }^{22}$ on tobacco-related oral mucosal lesions showed that bidi smoke also contains much higher concentrations of several toxic agents, such as hydrogen cyanide, carbon monoxide, ammonia, volatile phenols, and carcinogenic aromatic hydrocarbons, such as benzopyrene, which is one of most potent of these carcinogens, binds to nucleoproteins, and is mutagenic

Table 2: Stage wise Mean \pm SD of bidi index of case group patients

\begin{tabular}{lll}
\hline Stage & No. of patients (case) & Mean \pm SD \\
\hline I & 10 & $198.60 \pm 82.35$ \\
II & 20 & $300.26 \pm 183.61$ \\
III & 16 & $620.62 \pm 241.22$ \\
IV & 4 & $1,407.50 \pm 119.03$ \\
\hline
\end{tabular}

I vs II: $p<0.05$, Sig; II vs III: $p<0.01$, Sig; I vs III: $p<0.001$, HS; II vs IV: $p<0.001$, HS; I vs IV: $p<0.001$, HS; III vs IV: $p<0.001$, HS; HS, highly significant; NS, nonsignificant 
as well as carcinogenic. ${ }^{23-25}$ As reported in the studies of Reddy and Shaik ${ }^{26}$ and WHO's IARC (The International Agency for Research on Cancer) monographs, ${ }^{27}$ it is known that the nicotine content in smoked tobacco products is found to be much higher than that in the smokeless (chewing) tobacco products. The habits of smoking showed cytomorphological changes, indicating an increase in the nuclear diameter (ND) and reduction in cellular diameter (CD) of the cell. Increase in nuclear size could be produced as an inflammatory change due to chronic irritation of the oral mucosa caused by tobacco habits. This explains the effect of tobacco products on the epithelial cells. The results of the study conducted by Bánóczy et $\mathrm{al}^{28}$ showed that the permeability to the tobacco carcinogen, nitrosonornicotine for leukoplakic tissue, was higher than for normal control buccal specimens. The tendency for an increased mucosal permeability in smokers would seem to support this assertion. The hyperplastic and hyperkeratotic epithelial changes seen in the leukoplakia lesion represents a protective reaction of the tissue. Oral mucosa constantly irritated by tobacco use, as in the individuals of our study, might thus be turning over rapidly and so be more permeable to carcinogens. This irritation is probably the result of chemical components of tobacco that may directly stimulate the epithelial keratinocytes and/or induce an effect by activating cells in the connective tissue.

Our study shows that in the case group, out of 27 homogenous leukoplakia lesions, 8 (29.63\%) exhibited no dysplasia while $17(62.96 \%)$ turned out to be mild dysplasia and $2(7.41 \%)$ were reported as moderate dysplasia; 23 patients out of 50 patients had nonhomogenous leukoplakia in the speckled or erythroleukoplakia form (Table 3). All patients with this clinical form exhibited epithelial dysplasia. It is evident from this study that nonhomogenous leukoplakia contributed to higher grades of dysplasia, and therefore, there is an obvious

Table 3: Distribution according to histopathological diagnosis and clinical lesion grading

\begin{tabular}{llll}
\hline \multirow{2}{*}{$\begin{array}{l}\text { Histopathological } \\
\text { diagnosis }\end{array}$} & \multicolumn{3}{c}{ Clinical lesion } \\
\cline { 2 - 3 } & $\begin{array}{l}\text { Homogenous } \\
\text { leukoplakia }\end{array}$ & $\begin{array}{l}\text { Nonhomogenous } \\
\text { leukoplakia }\end{array}$ & Total \\
\hline No dysplasia & 8 & 0 & 8 \\
& $(29.63)$ & $(0.00)$ & $(16.00)$ \\
Mild dysplasia & 17 & 5 & 22 \\
& $(62.96)$ & $(21.74)$ & $(44.00)$ \\
Moderate dysplasia & 2 & 14 & 16 \\
& $(7.41)$ & $(60.87)$ & $(32.00)$ \\
Severe dysplasia & 0 & 4 & 4 \\
& $(0.00)$ & $(17.39)$ & $(8.00)$ \\
\hline Total & 27 & 23 & 50 \\
& $(100.00)$ & $(100.00)$ & $(100.00)$ \\
\hline
\end{tabular}

congruence between the risk of malignant development and nonhomogeneous leukoplakia lesions with epithelial dysplasia, which is also consistent with the studies conducted by Silverman et $\mathrm{al}^{29}{ }^{29}$ Schepman and van der Waal, ${ }^{30}$ and Bánóczy and Csiba. ${ }^{31}$ The degree of dysplasia in the case group increased with higher grades of staging. The connective tissue changes of epithelial dysplasia in the biopsy specimens of the case group showed features of chronic inflammatory cell infiltration and degenerative changes of hyaline and elastic fibers. Epithelial dysplasia can be found in biopsies of homogeneous leukoplakia, but is more commonly diagnosed in nonhomogeneous leukoplakias. ${ }^{31-33}$ From our study, it is evident that nonhomogenous leukoplakia contributed to higher grades of dysplasia. This is in agreement with the studies of Jaber et $\mathrm{al}_{1}{ }^{11}$ Warnakulasuriya et $\mathrm{al}^{34}$ and van der Waal. ${ }^{3}$ In the present study, it is evident that clinically diagnosed type of leukoplakia has a significant role in the eventual outcome of the lesion in the histopathological diagnosis, and thereby alarms the clinician regarding the appearance of this premalignant lesion. The histological changes were correlated with the clinical appearance and subsequent clinical course.

Epithelial dysplasia is classified into mild, moderate, and severe grades, based on the number of individual histological features necessary to be present for diagnosis of the three grades or by an assessment of the extension of the cytological changes from the basal cell layer and upward. The highest frequencies of dysplastic features found were basal cell hyperplasia, hyperkeratosis, acanthosis, and increased nuclear to cytoplasmic ratio. The features of severity in dysplasia is characterized by cellular and nuclear pleomorphism, loss of stratification and adhesion, keratin pearl formation and individual cell keratinization, and abnormal and increased mitotic figures. ${ }^{33}$ Dysplastic leukoplakias have a high propensity to progress to invasive squamous cell carcinoma. Studies indicate that an immunodeficient state could allow the precancers to transform into invasive malignancy. Increased levels of circulating immune complexes and suppressor cells in these patients suggest immunologic abnormalities. Natural killer cell is capable of lysing tumor-related and virally infected cells without prior sensitization. Interferon-mediated cytotoxic activity in host defense against tumor transformation contributes to the immunosurverillance mechanism. ${ }^{35}$

\section{SUMMARY AND CONCLUSION}

The study was conducted among patients of Chhattisgarh state to compare the clinicopathologic picture of oral leukoplakia and correlate the clinical severity with habits. Habit index of both groups were determined to check for 
any correlation. Thorough clinical examination followed by incisional biopsy of the 50 patients of case group was done, and histopathological evaluation was carried out. Within the limits of this study and on the basis of results obtained, the following conclusions may be drawn:

- Higher bidi index in the experimental group contributed significantly for severe stages of lesion and thereby indicates its probable progression toward malignancy.

- Nonhomogenous leukoplakia of the speckled subtype exhibited moderate and severe epithelial dysplasia. Hence the clinical appearance of the premalignant lesion predicts the risk of subsequent malignant transformation of the disease.

To conclude, our study highlights and confirms the fact stated in other similar studies that clinical and pathological staging correlates very well in oral leukoplakia. We also believe that habit modification and cessation appears to be the most appropriate primary and secondary preventive measure in overall management of oral leukoplakia. Quantification of habits highlights the fact that multifactorial etiology/risk factors in relation to oral leukoplakia must be kept in mind by the clinician while educating and motivating the patient to quit habits and for effective management of the lesion.

\section{ACKNOWLEDGMENTS}

Authors would like to thank the technical support of the auxiliary staff for their cooperation in the clinics and pathology technician who have dedicated their time and efforts toward attaining the results and others who indirectly contributed to the study.

\section{REFERENCES}

1. Speight PM, Farthing PM, Bouquot JE. The pathology of oral cancer and precancer. Curr Diagn Pathol 1996 Sep;3(3):165-176.

2. Rein CR, Goodman JJ. Leukoplakia buccalis. CA Cancer J Clin 1954 Sep;4(5):164-166.

3. van der Waal I. Potentially malignant disorders of the oral and oropharyngeal mucosa; terminology, classification and present concepts of management. Oral Oncol 2009 Apr-Mar;45(4-5):317-323.

4. Mehta FS, Gupta PC, Pindborg JJ. Chewing and smoking habits in relation to precancer and oral cancer. J Cancer Res Clin Oncol 1981;99(1-2):35-39.

5. International Institute for Population Sciences and ORC Macro International. National Family Health Survey (NFHS-3), 2005-06: India. Mumbai: IIPS; 2007. Vol. 2. p. 426-429.

6. Daftary DK, Murti PR, Bhonsle RB, Gupta PC, Mehta FS, Pindborg JJ. In: Prabhu SR, Wilson DF, Daftary DK, Johnson NW, editors. Oral Squamous cell Carcinoma. Oral diseases in the tropics. Oxford (UK): Oxford University Press; 1992. p. 429-448.

7. Hecht SS, Castonguay A, Chung FL, Hoffmann D. Carcinogenicity and metabolic activation of tobacco-specific nitrosamines: current status and future prospects. IARC Sci Publ 1984;(57):763-778.
8. Hoffmann D, Brunnemann KD, Prokopczyk B, Djordjevic MV. Tobacco-specific N-nitrosamines and Areca-derived N-nitrosamines: chemistry, biochemistry, carcinogenicity, and relevance to human. J Toxicol Environ Health 1994 Jan;41(1):1-52.

9. van der Waal I, Schepman KP, Vander Meij EH, Smeele LE. Oral leukoplakia: clinicopathological review. Oral Oncol 1997 Sep;33(5):291-301.

10. Lodi G, Porter S. Management of potentially malignant disorders: evidence and critique. J Oral Pathol Med 2008 Feb;37(2):63-69.

11. Jaber MA, Porter SA, Speight P, Eveson JW, Scully C. Oral epithelial dysplasia: clinical characteristics of western European residents. Oral Oncol 2003 Sep;39(6):589-596.

12. van der Waal I, Axéll T. Oral leukoplakia: a proposal for uniform reporting. Oral Oncol 2002 Sep;38(6):521-526.

13. Barnes L, Eveson JW, Reichart PA, Sidransky D, editors. World Health Organization classification of tumors: pathology and genetic of Head and neck tumors. World Health Organisation; IARC Press Lyon, France 2005.

14. Jaber MA, Porter SR, Scully C, Gilthorpe MS, Bedi R. The role of alcohol in non-smokers and tobacco in non-drinkers in the aetiology of oral epithelial dysplasia. Int J Cancer 1998 Jul 29;77(3):333-336.

15. Jahanbani J. Prevalence of oral leukoplakia and lichen planus in 1167 Iranian textile workers. Oral Dis 2003 Nov;9(6):302-304.

16. Yen AM, Chen SC, Chang SH, Chen TH. The effect of betel quid and cigarette on multistate progression of oral premalignancy. J Oral Pathol Med 2008 Aug;37(7):417-422.

17. Bánóczy J, Gintner Z, Dombi C. Tobacco use and oral leukoplakia. J Dent Educ 2001 Apr;65(4):322-327.

18. Dietrich T, Reichart PA, Scheifele C. Clinical risk factors of oral leukoplakia in a representative sample of the US population. Oral Oncol 2004 Feb;40(2):158-163.

19. Gupta PC. A study of dose-response relationship between tobacco habits and oral leukoplakia. Br J Cancer 1984 Oct;50(4): 527-531.

20. Macigo FG, Mwaniki DL, Guthua SW, Njeru EK. Influence of cigarette filters on the risk of developing oral leukoplakia in a Kenyan population. Oral Dis 2001 Mar;7(2):101-105.

21. Thankappan KR, Thresia CU. Tobacco use and social status in Kerala. Indian J Med Res 2007 Oct;126:300-308.

22. Mehta FS, Hamner JE. Tobacco-related oral mucosal lesions and conditions in India. A guide for dental students, dentists and physicians. Bombay: Tata Institute of Fundamental Research; 1993.

23. Hoffmann D, Hoffmann I. The changing cigarette: chemical studies and bioassays. In: Smoking and tobacco control monograph no. 13. Chapter 5; p. 159-192.

24. HoffmannD,MelikianA,AdamsJD, Brunnemann KD, Haley NJ. New aspects of tobacco carcinogenesis. Carcinog Compr Surv 1985;8:239-256.

25. Pakhale SS, Sarkar S, Jayant K, Bhide SV. Carcinogenicity of Indian Bidi and cigarette smoke condensate in Swiss albino mice. J Cancer Res Clin Oncol 1988;114(6): 647-649.

26. Reddy SS, Shaik HA. Estimation of nicotine content in popular Indian brands of smoking and chewing tobacco products. Indian J Dent Res 2008 Apr-Jun;19(2):88-91.

27. World Health Organization. Tobacco smoke and involuntary smoking. IARC Monographs on the Evaluation of Carcinogenic Risks to Humans. Vol. 83. World Health Organization International Agency for Research on Cancer; Lyon, France 2004. 
28. Bánóczy J,Squier CA, KremerM, Wertz PW, Kovesi G,SzendeB, Dombi C. The permeability of oral leukoplakia. Eur J Oral Sci 2003 Aug;111(4):312-315.

29. Silverman S Jr, Gorsky M, Lozada F. Oral leukoplakia and malignant transformation - a follow-up study of 257 patients. Cancer 1984 Feb 1;53(3):563-568.

30. Schepman KP, Van der Waal I. A proposal for a classification and staging system for oral leukoplakia: a preliminary study. Eur J Cancer B Oral Oncol 1995 Nov;31B:396-398.

31. Bánóczy J, Csiba A. Occurrence of epithelial dysplasia in oral leukoplakia. Analysis and follow-up study of 12 cases. Oral Surg Oral Med Oral Pathol Oral Radiol Endod 1976 Dec;42(6):766-774.
32. Kaugars GE, Burns JC, Gunsolley JC. Epithelial dysplasia of the oral cavity and lips. Cancer 1988 Nov 15;62(10):2166-2170.

33. Reibel J. Prognosis of oral pre-malignant lesions: significance of clinical, histopathological, and molecular biological characteristics. Crit Rev Oral Biol Med 2003;14(1):47-62.

34. Warnakulasuriya S, Johnson NW, van der Waal I. Nomenclature and classification of potentially malignant disorders of the oral mucosa. J Oral Pathol Med 2007 Nov;36(10):575-580.

35. Pillai MR, Balaram P, Kannan S, Sudha L, Nalinakumari KR, Hareendran NK, Nair MK. Interferon activation of latent natural killer cells and alteration in kinetics of target cell lysis: clinical implications for oral precancerous lesions. Oral Surg Oral Med Oral Pathol 1990 Oct;70(4):458-461. 